\title{
Adherence to a COPD treatment guideline among patients in Hong Kong
}

This article was published in the following Dove Press journal: International journal of COPD

\author{
Ka Pang Chan' \\ Fanny WS Ko' \\ Hok Sum Chan² \\ Mo Lin Wong ${ }^{3}$ \\ Thomas YW Mok ${ }^{4}$ \\ Kah Lin $\mathrm{Choo}^{5}$ \\ David SC Hui' \\ 'Department of Medicine and \\ Therapeutics, The Chinese University \\ of Hong Kong, Prince of Wales \\ Hospital, 'Department of Medicine, \\ Alice Ho Miu Ling Nethersole \\ Hospital, ${ }^{3}$ Department of Medicine \\ and Geriatrics, Caritas Medical \\ Centre, ${ }^{4}$ Respiratory Medical \\ Department, Kowloon Hospital, \\ ${ }^{5}$ Department of Medicine, North \\ District Hospital, Hong Kong
}

Background: This study aimed to assess the adherence rate of pharmacological treatment to the Global Initiative for Chronic Obstructive Lung Disease (GOLD) guideline published in 2011 and the prevalence of comorbidities among patients with COPD in Hong Kong (HK).

Methods: Patients were recruited from five tertiary respiratory centers and followed up for 12 months. Data on baseline physiological, spirometric parameters, use of COPD medications and coexisting comorbidities were collected. The relationship between guideline adherence rate and subsequent COPD exacerbations was assessed.

Results: Altogether, 450 patients were recruited. The mean age was $73.7 \pm 8.5$ years, and $92.2 \%$ of them were males. Approximately $95 \%$ of them were ever-smokers, and the mean post-bronchodilator (BD) forced expiratory volume in 1 second was $50.8 \% \pm 21.7 \%$ predicted. The mean COPD Assessment Test and modified Medical Research Council Dyspnea Scale were $13.2 \pm 8.1$ and $2.1 \pm 1.0$, respectively. In all, five (1.1\%), $164(36.4 \%)$, eight (1.8\%) and 273 (60.7\%) patients belonged to COPD groups A, B, C and D, respectively. The guideline adherence rate for pharmacological treatment ranged from $47.7 \%$ to $58.1 \%$ in the three clinic visits over 12 months, with overprescription of inhaled corticosteroids (ICS) and underutilization of long-acting BDs in group B COPD patients. Guideline nonadherence was not associated with increased risk of exacerbation after adjustment of confounding variables. However, this study was not powered to assess a difference in exacerbations. In all, $80.9 \%$ of patients had at least one comorbidity.

Conclusion: A suboptimal adherence to GOLD guideline 2011, with overprescription of ICS, was identified. The commonly found comorbidities also aligned with the trend observed in other observational cohorts.

Keywords: COPD, GOLD guideline, adherence

\section{Background}

COPD is one of the leading health burdens worldwide and has been estimated to become the third leading cause of death by $2030 .{ }^{1}$ In Hong Kong (HK), 10.7\% of the populations are chronic smokers. ${ }^{2}$ Based on the Epidemiology and Impact of COPD (EPIC) Asia survey by Lim et al, ${ }^{3}$ the estimated prevalence of stable COPD was $7.7 \%$, and $16.1 \%$ in these COPD patients met the definition of severe symptomatic phenotype. In the same study, a significant proportion of these COPD patients also reported "very poor" to "fair" general health status and unplanned health care utilization. ${ }^{3}$ In 2005, COPD was the third leading cause of respiratory mortality and ranked second as a respiratory cause of hospitalization and inpatient bed-days in $\mathrm{HK} .{ }^{4}$ In the US, the hospitalizations and readmissions for acute exacerbation of COPD (AECOPD) are prevalent and costly. ${ }^{5,6}$

To meet the rising cost and quality of COPD care, the Global Initiative for Chronic Obstructive Lung Disease (GOLD) guideline was first released in 2001. Since its
Correspondence: David SC Hui Department of Medicine and

Therapeutics, The Chinese University of Hong Kong, Prince of Wales Hospital,

30-32 Ngan Shing Street, Sha Tin,

New Territories, Hong Kong

Tel +85235052785

Fax +852 26375396

Email dschui@cuhk.edu.hk
International Journal of COPD 20I7:12 337|-3379

3371

Dovepress f $y$ in $\mathbf{0}$

http://dx.doi.org/10.21471COPD.S147070 (c) (i) (5) 2017 Chan et al. This work is published and licensed by Dove Medical Press Limited. The full terms of this license are available at https://www.dovepress.com/terms.php (c) ${ }_{\mathrm{BY}} \mathrm{NC}$ and incorporate the Creative Commons Attribution - Non Commercial (unported, v3.0) License (http://(creativecommons.org/licenses/by-nc/3.0/). By accessing the work you hereby accept the Terms. Non-commercial uses of the work are permitted without any further permission from Dove Medical Press Limited, provided the work is properly attributed. For permission for commercial use of this work, please see paragraphs 4.2 and 5 of our Terms (https://www.dovepress.com/terms.php). 


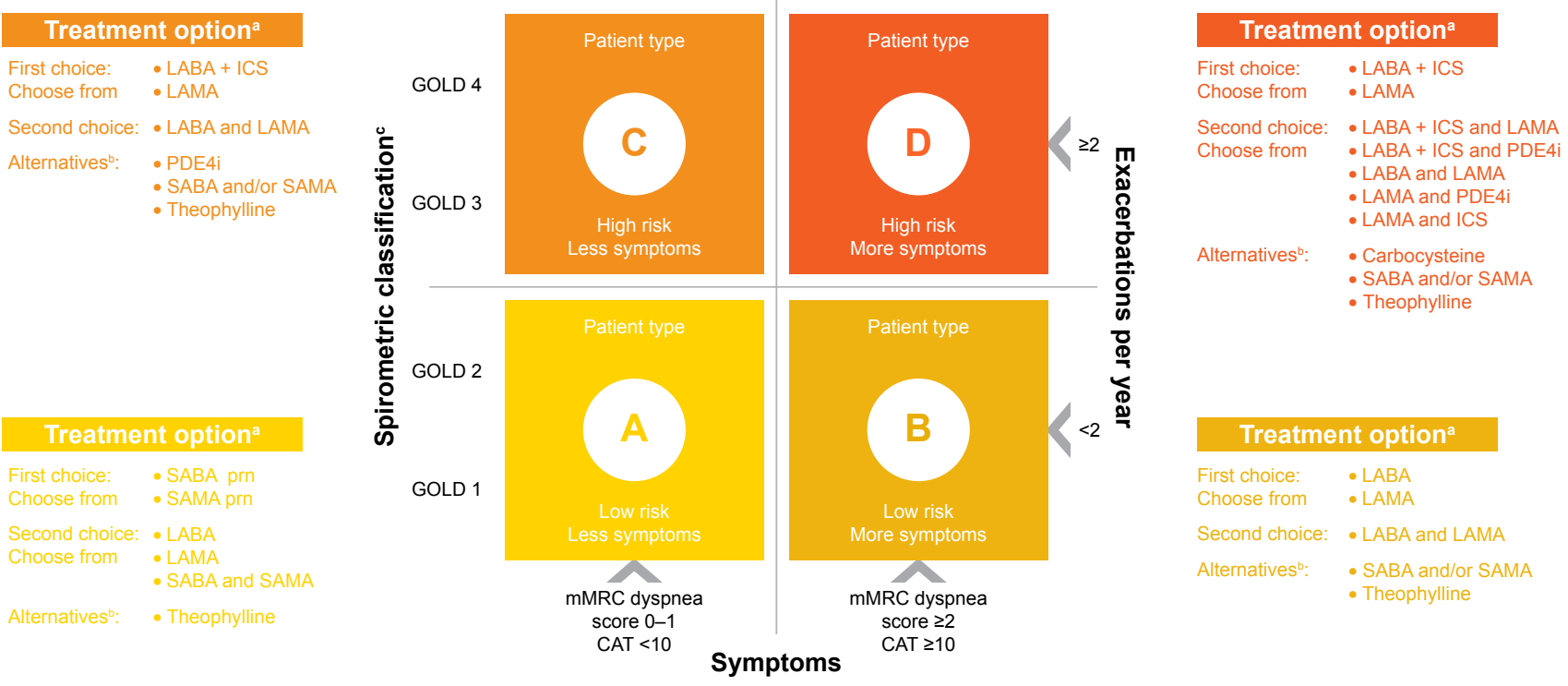

Figure I COPD grouping and pharmacological management recommended by GOLD guideline 201 I.

Notes: Adapted from Global initiative for chronic obstructive lung disease (GOLD). Global strategy for the diagnosis, management and prevention of chronic pulmonary disease, 2011 with permission. ${ }^{7}$ Treatment options within each choice are mentioned in alphabetical order and therefore not necessarily in order of preference. ${ }^{b}$ Alternative treatment to be used alone or in combination with other options in the first and second choices. ${ }^{~} \mathrm{GOLD}$ I: FEV,$\geq 80 \%$ predicted, GOLD 2 : $50 \% \leq \mathrm{FEV}, \leq 80 \%$ predicted, GOLD 3: $\mathrm{FEV}, \leq 50 \%$ predicted and GOLD 4: $\mathrm{FEV},<30 \%$ predicted or $\mathrm{FEV}$, predicted plus chronic respiratory failure.

Abbreviations: CAT, COPD Assessment Test; FEV , forced expiratory volume in I second; GOLD, Global Initiative for Chronic Obstructive Lung Disease; ICS, inhaled corticosteroids; LABA, long-acting $\beta_{2}$-agonist; LAMA, long-acting muscarinic antagonist; mMRC, modified Medical Research Council; PDE4i, phosphodiesterase 4 inhibitors; prn, as needed (pro renata); SABA, short-acting $\beta_{2}$-agonist; SAMA, short-acting muscarinic antagonist.

publication, it quickly became an important reference for COPD treatment. There was a major revision of the GOLD guideline in 2011, with incorporation of functional level and risk of future exacerbation, ${ }^{7}$ based on the fact that COPD is a disease with multifaceted nature and the management plan should not rely on airflow limitation alone. According to the spirometric parameters, history of recent exacerbation, functional status in terms of modified Medical Research Council (mMRC) score or COPD Assessment Test (CAT) score, COPD patients are categorized into groups $A$ to $\mathrm{D}$ accordingly (Figure 1). Within each group of patients, a set of medications are recommended for disease control and prevention of exacerbation. Bronchodilators (BDs), especially long-acting agents, are considered as the backbone of pharmacological treatment, either as first-line or alternative choices.

The attending physicians may not always adhere to the guideline, as seen in other common medical conditions. ${ }^{8}$ Despite the availability of the GOLD guideline and its recommendation of stage-based pharmacotherapy, many studies showed inadequate adherence. ${ }^{9-12}$ Reasons including poor familiarity with the GOLD guideline and difficulty in assessing response to therapy may contribute to suboptimal guideline adherence. ${ }^{12,13}$ It was reported that guidelineoriented pharmacotherapy might improve airflow limitation and lower health care cost. ${ }^{14,15}$
In addition, COPD is associated with various respiratory and non-respiratory comorbidities, which impose negative impacts on patients, leading to impaired functional status and a higher mortality rate. ${ }^{16}$ Scattered reports on the prevalence of COPD comorbidities in HK have been published, but data from large-scale studies are lacking. ${ }^{17,18}$

The primary objective of the current study was to evaluate the adherence rate of pharmacological treatment to the GOLD guideline published in 2011 in HK. The secondary objective was to investigate the prevalence of comorbidities among COPD patients in the local public hospitals.

\section{Methods}

\section{Study design and patient recruitment}

This 12-month, multicenter observational study was conducted in five public hospitals with tertiary referral clinics in HK between March 2013 and February 2015. Consecutive patients were recruited from outpatient clinics of these hospitals if a diagnosis of COPD was made according to the GOLD guideline and results of spirometry testing were either available within 6 months prior to study enrollment or could be performed at the baseline visit. Concurrent participation in another clinical trial was the only exclusion criterion. Informed consents were obtained from the patients or provided by a legally acceptable representative 
of the patient if they were incapable of doing so. The study was approved by the corresponding ethics committees of the participating hospitals (The Joint Chinese University of Hong Kong - New Territories East Cluster Clinical Research Ethics Committee, Research Ethics Committee [Kowloon Central/Kowloon East] and Kowloon West Cluster Research Ethics Committee).

The observational period of 12 months covered three clinic visits every 6 months for each patient. In the baseline visit (visit 1), patients were treated according to the attending physicians' decision and baseline clinical data were collected. The second (visit 2) and final (visit 3) visits were conducted at months 6 and 12, respectively. As this study was designed to reflect the real-life setting of clinical practice, the assignment of the patient to the therapy would be decided by the attending physicians and not predefined by the study protocol. In order to evaluate the adherence to the GOLD guideline 2011, COPD treatment, concomitant medications, adjustment of medication, reasons of treatment change and use of rescue medications were recorded. Throughout the study period, the occurrence of exacerbations and death were recorded. Spirometric measurements were performed according to the criteria recommended by the American Thoracic Society and referenced according to the Global Lung Function Initiative spirometric prediction equations. ${ }^{19,20}$

\section{Sample size calculation}

An earlier study estimated that 139,000 moderate or severe COPD cases in people aged $\geq 30$ years occurred in HK using a COPD prevalent model, which implied a $3.5 \%$ prevalence rate. ${ }^{21}$ The sample size calculation was based on precision approach. We planned a random sample to seek a $95 \%$ confidence interval $(\mathrm{CI})$ that the sample was representative of the COPD population in HK. As this was a measure of adherence of a new guideline, the rate of adherence was uncertain and conservatively assumed to be $50 \%$. Assuming a $95 \% \mathrm{CI}$, margin of error of $5 \%$ and variability of a rate of $50 \%$, the estimated sample size would be 385 . Considering an attrition rate of $10 \%$ during the study, a total of 428 subjects were required.

\section{Statistical analysis}

Baseline characteristics including demographic data, spirometric parameters and history of exacerbations of patients were summarized by descriptive statistics. Continuous variables were represented by mean and median, and categorical data were represented by values in percentage. The status of guideline adherence was stratified into adherent, overtreated and undertreated groups. The combinations of pharmacological treatment of each group are listed in Table 1. The number of COPD exacerbation episodes throughout the 12 months was collected for those patients with the same status of guideline compliance across visits 1 and 2. The Mann-Whitney $U$ test was used to compare the number of exacerbations between adherent, overtreated and undertreated groups. Linear regression analysis with adjustment of confounding variables was performed if any significant association was found between treatment adherence status and exacerbation rate over 12 months. For the incidence of different comorbidities among individual COPD groups, they were compared using the chi-square test. All tests were two tailed, and significance was set at 0.05 . Data analyses were performed with IBM SPSS Statistics software version 22.0.

\section{Results}

A total of 450 patients were recruited from the respiratory clinics of five hospitals. After 12 months of observation, $68(15.1 \%)$ patients dropped out from the study. Approximately half $(34,54.0 \%)$ of the patients died, and approximately onethird $(19,30.2 \%)$ of them were lost to follow-up (Figure 2).

\section{Patient characteristics}

Baseline demographics are shown in Table 2. The mean number of AECOPD before enrollment was 1.6 \pm 1.9 episodes, and $\sim 60 \%$ of patients belonged to GOLD group D according to the guideline classification.

Table I Definition of overtreatment and undertreatment for different groups of COPD patients

\begin{tabular}{cl}
\hline Overtreatment (presence of these & medication combinations) \\
Group A & LABA + LAMA, any ICS, any PDE4i \\
Group B & Any ICS, any PDE4i \\
Group C & LABA + LAMA + ICS \\
& LAMA + ICS \\
Undertreatment (absence of these medication combinations) \\
Group B \\
LABA, LAMA \\
Group C \\
LAMA, LABA + ICS, LABA + LAMA \\
LABA + ICS, LAMA alone \\
LABA + LAMA + ICS \\
LABA + ICS + PDE4i \\
LAMA + LABA, LAMA + PDE4i \\
LAMA + ICS
\end{tabular}

Notes: "Overtreated" group applies to patients of groups A, B and C using a pharmacological treatment combination more than recommended by the guideline, and "undertreatment" group applies to patients of groups B, C and D using a suboptimal pharmacological treatment combination. ICS alone are considered as undertreatment in groups $B, C$ and $D$ and as overtreatment in group $A$.

Abbreviations: ICS, inhaled corticosteroids; LABA, long-acting $\beta_{2}$-agonist; LAMA, long-acting muscarinic antagonist; PDE4i, phosphodiesterase 4 inhibitors. 


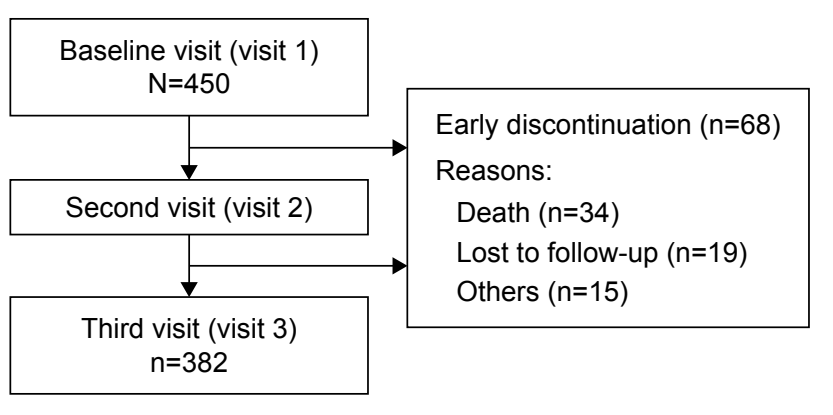

Figure 2 Enrollment and outcomes.

\section{Treatment characteristics}

The frequency of COPD medication use is shown in Table 3. Short-acting $\beta_{2}$-agonist (SABA) was the most commonly prescribed inhaler with $>85 \%$ of groups $\mathrm{B}, \mathrm{C}$ and $\mathrm{D}$ patients having received it throughout the study period. Inhaled corticosteroids (ICS) alone were not commonly used in groups A

Table 2 Baseline sociodemographics and clinical characteristics

\begin{tabular}{|c|c|c|}
\hline Variable & Mean \pm SD & n (\%) \\
\hline Age, years & $73.7 \pm 8.5$ & \\
\hline \multicolumn{3}{|l|}{ Gender } \\
\hline Male & & $413(92.2)$ \\
\hline Female & & $35(7.8)$ \\
\hline \multicolumn{3}{|l|}{ Smoking status } \\
\hline Current smoker & & $65(14.5)$ \\
\hline Ex-smoker & & $36 \mid(80.4)$ \\
\hline Nonsmoker & & $23(5.1)$ \\
\hline Smoking packs/year & $39.5 \pm 32.3$ & \\
\hline \multicolumn{3}{|l|}{ (non-smokers excluded) } \\
\hline \multicolumn{3}{|l|}{ Working status } \\
\hline Employed & & $39(8.7)$ \\
\hline Unemployed & & $6(1.3)$ \\
\hline Retired & & $40 I(89.9)$ \\
\hline Body weight, kg & $56.4 \pm 11.0$ & \\
\hline Body height, cm & $162.2 \pm 7.3$ & \\
\hline $\mathrm{BMI}, \mathrm{kg} / \mathrm{m}^{2}$ & $21.4 \pm 3.8$ & \\
\hline Pre-BD FEV $/ \mathrm{L}$ & $1.0 \pm 0.5$ & \\
\hline Pre-BD FEV $1 \%$ predicted & $47.2 \pm 19.7$ & \\
\hline Post-BD FEV,/L & $I . I \pm 0.5$ & \\
\hline Post-BD FEV $1 \%$ predicted & $50.8 \pm 21.7$ & \\
\hline CAT score & $13.2 \pm 8.1$ & \\
\hline mMRC dyspnea score & $2.1 \pm 1.0$ & \\
\hline Number of exacerbations in the last & $1.6 \pm 1.9$ & \\
\hline \multicolumn{3}{|l|}{12 months } \\
\hline$\geq 2$ exacerbations in the last 12 months & & $165(37.4)$ \\
\hline \multicolumn{3}{|l|}{ Baseline COPD group } \\
\hline A & & $5(1.1)$ \\
\hline B & & $164(36.4)$ \\
\hline C & & $8(1.8)$ \\
\hline$D$ & & $273(60.7)$ \\
\hline
\end{tabular}

Abbreviations: BD, bronchodilator; BMI, body mass index; CAT, COPD Assessment Test; $\mathrm{FEV}_{1}$, forced expiratory volume in I second; mMRC, modified Medical Research Council; SD, standard deviation. and B patients. However, ICS was used in combination, especially with long-acting $\beta_{2}$-agonist (LABA), contributing to a high rate of prescription in all COPD stages. Except for patients in groups A and C, the use of ICS in COPD patients could be up to $>80 \%$. Among different BDs, the use of any LABA outweighed the use of any long-acting muscarinic antagonist (LAMA) most of the time. More than $50 \%$ of patients received LABA at each visit, with an increasing trend observed. The rate of LABA use approached 90\% among group $D$ patients. Such a high rate of LABA prescription was mainly due to the use of LABA/ICS combination. Theophylline was quite commonly used, but roflumilast was rarely used in the 12-month period.

Physicians could adjust the treatment at each clinical visit according to the medical need (Table 4). Among those who had changed treatment, the most common reason was insufficient disease control.

\section{Primary objective}

\section{Guideline adherence on pharmacological treatment}

There was a decreasing trend for the adherence rate throughout this 12 -month study, with $58.2 \%$ at baseline, $47.7 \%$ at month 6 and 51.6\% at month 12 (Table 5). The guideline adherence was mainly observed in group D patients, with $>95 \%$ of treatment compliance falling within this group of patients.

Although both undertreatment and overtreatment contributed to guideline nonadherence, the overtreatment group shared a greater proportion. More patients were undertreated in group B than those in group D $(p<0.001)$, and group B patients contributed to $>90 \%$ of the proportion in the overtreatment group at all three visits. A significant proportion of overtreatment was due to the use of ICS, either alone or together with LABA, in patients of groups A and B.

\section{Association between guideline adherence and AECOPD}

Adherent group patients had significantly more episodes of AECOPD when compared with the overtreated group $(p<0.001)$ and undertreated group $(p<0.001)$. The figures are shown in Table 6 . Analysis was performed and confirmed significant associations between COPD GOLD grouping, frequency of AECOPD 1 year prior to study enrollment, treatment adherence and subsequent episodes of AECOPD. After adjustment for COPD GOLD grouping and frequency of AECOPD 1 year prior to study enrollment, patients who were treated according to guideline had more episodes of AECOPD than those who were undertreated $(p<0.001)$. 


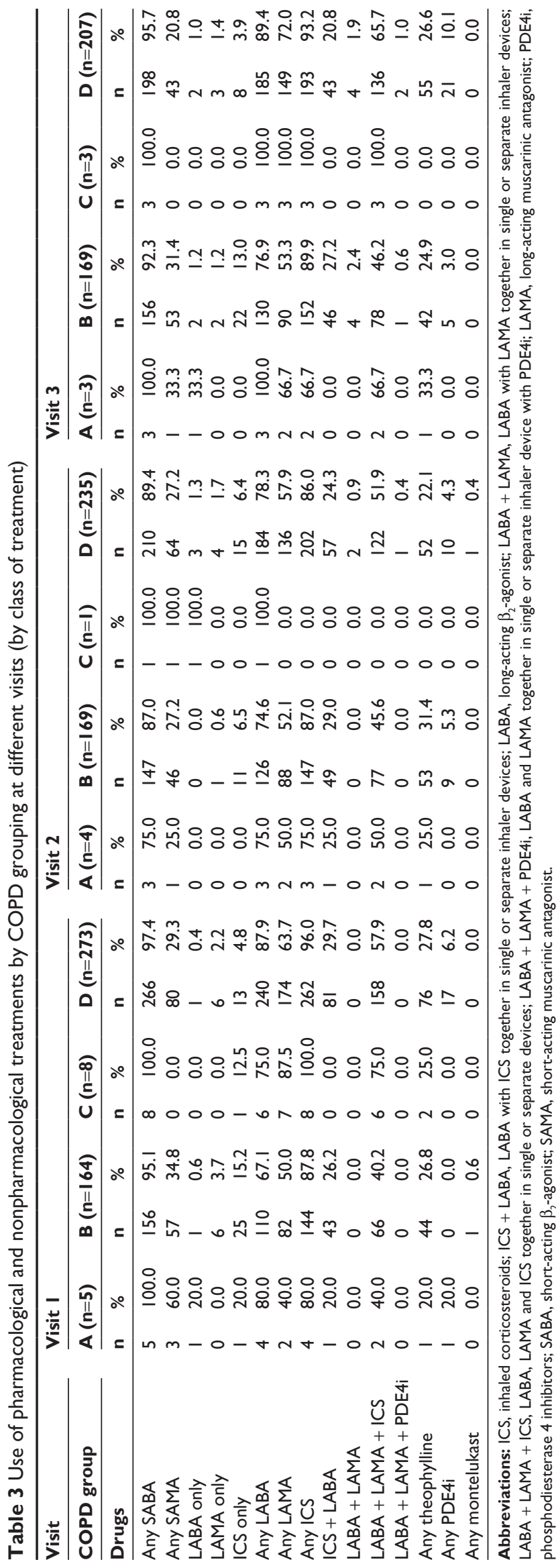

Table 4 Reasons for change of pharmacological therapy

\begin{tabular}{|c|c|c|c|}
\hline Treatment changed & $\begin{array}{l}\text { Visit I } \\
(n=446)\end{array}$ & $\begin{array}{l}\text { Visit } 2 \\
(n=407)\end{array}$ & $\begin{array}{l}\text { Visit } 3 \\
(n=380)\end{array}$ \\
\hline $\begin{array}{l}\text { Number of patients who had } \\
\text { treatment changed (\%) }\end{array}$ & $123(27.6)$ & $123(30.2)$ & $107(28.2)$ \\
\hline \multicolumn{4}{|l|}{ Reasons } \\
\hline Insufficient disease control, n (\%) & $104(84.6)$ & $89(72.4)$ & $78(72.9)$ \\
\hline Tolerability issues, $\mathrm{n}(\%)$ & $9(7.3)$ & 14 (I I.4) & II (2.9) \\
\hline Compliance issues, $\mathrm{n}(\%)$ & $\mathrm{I}(0.8)$ & $2(1.6)$ & $5(1.3)$ \\
\hline Inhaler device issues, $\mathrm{n}(\%)$ & $6(4.9)$ & $7(5.7)$ & $4(1.1)$ \\
\hline Others, n (\%) & $9(7.3)$ & 14 (II.4) & $10(2.6)$ \\
\hline
\end{tabular}

Note: Some patients had more than one reason for change of therapy.

However, there was no association between overtreatment and exacerbation rate over 1 year $(p=0.593)$.

\section{Secondary objectives}

In all, 364 (80.9\%) patients had coexisting comorbidities at the baseline visit (Table 7), and hypertension (HT) was the most common single disease (40.7\%). Patients who were in groups B and D at baseline had higher prevalence of comorbidities ( $74.4 \%$ and $85.3 \%$, respectively) than those in COPD groups $\mathrm{A}$ and $\mathrm{C}$ at baseline $(60.0 \%$ and $75.0 \%$, respectively; $p=0.035$ ). Group $\mathrm{D}$ patients had more coexisting heart failure than group B patients.

\section{Discussion}

This 12-month observational study reflects the local prescription pattern of pharmacological treatment in the hospital respiratory clinic setting. The baseline patient characteristics were comparable with other local and international COPD studies, which comprised mainly male heavy smokers, with similar body mass index (BMI) and forced expiratory volume in 1 second $\left(\mathrm{FEV}_{1}\right)$ levels. ${ }^{18,22-24}$ The spectrum of COPD included patients of groups A-D, with a distribution skewed toward the categories with more symptoms (groups B and D) with relatively high mMRC and CAT scores. This finding is different from the data obtained in the EPIC Asia population-based study, which was mainly a cross-sectional population-based survey. ${ }^{3}$ Instead, this type of patient distribution has been observed in the FLAME trial. ${ }^{25}$

To date, this has been the only large-scale observational study in HK investigating the treatment adherence to GOLD guideline 2011 on COPD patients. The adherence rate shown in this study was suboptimal, although there was no standard threshold of satisfactory adherence. The adherence rate to the GOLD guideline 2011 varied from $18.0 \%$ to $70.1 \%$ for various overseas studies..$^{22,26-28}$ The main reason for guideline nonadherence in the current study was due 
Table 5 Adherence rate to GOLD guideline $201 \mathrm{I}$

\begin{tabular}{|c|c|c|c|c|c|}
\hline Visit & $\begin{array}{l}\text { COPD } \\
\text { groups }\end{array}$ & $\begin{array}{l}\text { Total number } \\
\text { of patients }\end{array}$ & $\begin{array}{l}\text { Adherent, } \\
\text { n (\%) }\end{array}$ & $\begin{array}{l}\text { Overtreated, } \\
\text { n (\%) }\end{array}$ & $\begin{array}{l}\text { Undertreated, } \\
\text { n (\%) }\end{array}$ \\
\hline \multirow[t]{5}{*}{1} & Overall & 450 & $262(58.2)$ & 130 (28.9) & $58(12.9)$ \\
\hline & A & 5 & I (0.2) & $4(0.9)$ & $N / A$ \\
\hline & B & 164 & $7(1.6)$ & $119(26.4)$ & $38(8.4)$ \\
\hline & C & 8 & $0(0.0)$ & $7(1.6)$ & I $(0.2)$ \\
\hline & $D$ & 273 & $254(56.4)$ & N/A & $19(4.2)$ \\
\hline \multirow[t]{5}{*}{2} & Overall & 409 & $195(47.7)$ & $140(34.2)$ & $74(18.1)$ \\
\hline & A & 4 & I (0.2) & $3(0.7)$ & N/A \\
\hline & B & 169 & I $(0.2)$ & $137(33.5)$ & 31 (7.6) \\
\hline & C & 1 & $0(0.0)$ & $0(0.0)$ & I $(0.2)$ \\
\hline & $D$ & 235 & $193(47.2)$ & N/A & $42(10.3)$ \\
\hline \multirow[t]{5}{*}{3} & Overall & 382 & $197(5 \mid .6)$ & $136(35.6)$ & 49 (12.8) \\
\hline & A & 3 & I (0.2) & $2(0.5)$ & $\mathrm{N} / \mathrm{A}$ \\
\hline & B & 169 & $4(1.0)$ & |3| (34.3) & $34(8.9)$ \\
\hline & C & 3 & $0(0.0)$ & $3(0.8)$ & $0(0.0)$ \\
\hline & D & 207 & $192(50.3)$ & $\mathrm{N} / \mathrm{A}$ & $15(3.9)$ \\
\hline
\end{tabular}

Note: The rate of guideline adherence and undertreatment remains similar over 12 months, but there was an increasing trend of overtreatment. Abbreviations: GOLD, Global Initiative for Chronic Obstructive Lung Disease; N/A, not applicable.

to overtreatment, especially the overuse of ICS in low-risk patients alone or in combination with other BDs, which had also been reported in a Turkish study. ${ }^{22}$ Long-acting BDs were indicated for group B patients, but they were underutilized. More than $65 \%$ of group B patients received LABA/ICS combination, but only a minor proportion of them received single or combined long-acting BDs. The widespread use of LABA/ICS combination may be explained by its longer marketing history and better availability in the public health care system, contributing to a much higher utilization rate than LAMA or LABA monotherapy. Concerns of ICS overuse have been studied frequently in the last few years, especially for its inferior efficacy of bronchodilation and higher risk of causing pneumonia. ${ }^{29,30}$

The pattern of oral pharmacological treatment in the current study is different from other studies. Quite a number of patients received oral theophylline during the study period. When comparing with other inhaled BDs, theophylline was much cheaper and its prescription was not restricted by the public health care system. Despite having more systemic side effects, it was an attractive choice of treatment across all four groups of local COPD patients. The use of roflumilast in patients of groups A and B is obviously out of the guideline recommendations, which suggested use of roflumilast in patients of groups $\mathrm{C}$ and $\mathrm{D}$. Although this practice was uncommon in the current study, it might reflect inadequate understanding of its indications.

The adherence rate to the GOLD guideline was shown to be variable by several studies. ${ }^{9-11}$ Nonadherence rates were reported in these studies, but only a few of them subdivided the types of nonadherence into categories of under- or overtreatment. ${ }^{26,28}$ The underlying reasons for guideline nonadherence were not evaluated in this study. We postulated that this would be due to inadequate symptom evaluation and suboptimal understanding of guideline recommendations.

The lack of adherence to clinical guidelines had been published before, and some of the barriers were due to the guideline itself. ${ }^{31}$ With regular updates based on the latest evidence, some of these problems can be solved or minimized. However, many obstacles for GOLD guideline adherence were reported, including inadequate familiarity of guideline, lack of perceived treatment benefit, low self-efficacy and time constraints. ${ }^{12,32}$ Multiple strategies have been advocated in different countries to enhance the guideline adherence

Table 6 Adherence rate to GOLD guideline $201 \mathrm{I}$ and exacerbation rate

\begin{tabular}{lllll}
\hline $\begin{array}{l}\text { Treatment } \\
\text { adherence }\end{array}$ & Total & $\begin{array}{l}\text { No } \\
\text { exacerbation }\end{array}$ & $\begin{array}{l}\text { Exacerbation } \\
\text { occurred }\end{array}$ & $\begin{array}{l}\text { Comparison with adherence } \\
\text { group on exacerbation }\end{array}$ \\
\hline $\begin{array}{l}\text { Adherence group } \\
\text { Overtreatment group }\end{array}$ & 183 & 57 & 126 & N/A \\
Undertreatment group & 86 & 51 & 35 & $p<0.00 I^{\mathrm{a}}$ \\
\hline
\end{tabular}

Note: apatients in the adherence group had more exacerbations than those overtreated or undertreated.

Abbreviations: GOLD, Global Initiative for Chronic Obstructive Lung Disease; N/A, not applicable. 
Table 7 Summary of comorbidities by baseline COPD groupings

\begin{tabular}{|c|c|c|c|c|c|c|}
\hline \multirow[t]{2}{*}{ Comorbidity, n (\%) } & \multicolumn{4}{|c|}{ Baseline COPD group by GOLD guideline $201 \mathrm{I}$} & \multirow[t]{2}{*}{$p$-value } & \multirow{2}{*}{$\begin{array}{l}\text { Total } \\
(\mathrm{N}=450)\end{array}$} \\
\hline & $A(n=5)$ & $B(n=164)$ & $C(n=8)$ & $D(n=273)$ & & \\
\hline \multirow[t]{2}{*}{ Any comorbidities } & $3(60.0)$ & $122(74.4)$ & $6(75.0)$ & $233(85.3)$ & $0.033^{\mathrm{a}, \mathrm{b}}$ & $364(80.9)$ \\
\hline & & & & & $0.005^{a, c}$ & \\
\hline HT & I (20.0) & $68(41.5)$ & $3(37.5)$ & III (40.7) & $0.920^{c}$ & I83 (40.7) \\
\hline DM & $2(40.0)$ & $14(8.5)$ & $\mathrm{I}(\mathrm{I} 2.5)$ & $36(13.2)$ & $0.163^{c}$ & $53(11.8)$ \\
\hline Old TB & $0(0.0)$ & $18(11.0)$ & $3(37.5)$ & $29(10.6)$ & $1.000^{c}$ & $50(11.1)$ \\
\hline IHD & $0(0.0)$ & $12(7.3)$ & $0(0.0)$ & $35(12.8)$ & $0.080^{c}$ & $47(10.4)$ \\
\hline $\mathrm{BPH}$ & $0(0.0)$ & $16(9.8)$ & $0(0.0)$ & $30(11.0)$ & $0.749^{c}$ & $46(10.2)$ \\
\hline Hyperlipidemia & $0(0.0)$ & $9(5.5)$ & I (I2.5) & $18(6.6)$ & $0.688^{c}$ & $28(6.2)$ \\
\hline Cardiac arrhythmia & $0(0.0)$ & $8(4.9)$ & $0(0.0)$ & $20(7.3)$ & $0.420^{c}$ & $28(6.2)$ \\
\hline Malignancy other than lung cancer & $0(0.0)$ & $5(3.0)$ & $2(25.0)$ & $18(6.6)$ & $0.125^{c}$ & $25(5.6)$ \\
\hline Heart failure & I (20.0) & $3(1.8)$ & $0(0.0)$ & $19(7.0)$ & $0.022^{\mathrm{a}, \mathrm{c}}$ & $23(5.1)$ \\
\hline Old CVA & $0(0.0)$ & $9(5.5)$ & $0(0.0)$ & I3 (4.8) & $0.822^{c}$ & $22(4.9)$ \\
\hline Bronchiectasis & $0(0.0)$ & $2(1.2)$ & $0(0.0)$ & $7(2.6)$ & $0.494^{c}$ & $9(2.0)$ \\
\hline Lung cancer & $0(0.0)$ & $\mathrm{I}(0.6)$ & $0(0.0)$ & $6(2.2)$ & $0.264^{c}$ & $7(1.6)$ \\
\hline Others & $0(0.0)$ & $45(27.4)$ & $4(50.0)$ & $86(31.5)$ & & I 35 (30.0) \\
\hline
\end{tabular}

Notes: Patients of groups B and D had a higher prevalence of comorbidities than those of groups A and C. Comparison between groups A and C was not performed due to the small number of patients. ${ }^{a}$ Clinically significant. ${ }^{\circ}$ Comparison between all COPD groups. ${ }^{\circ}$ Comparison between groups $\mathrm{B}$ and $\mathrm{D}$.

Abbreviations: BPH, benign prostatic hyperplasia; CVA, cerebrovascular accident; DM, diabetes mellitus; GOLD, Global Initiative for Chronic Obstructive Lung Disease; $H T$, hypertension; IHD, ischemic heart disease; TB, tuberculosis.

and physician awareness, leading to various degrees of success. ${ }^{9,12,33}$ Unfortunately, such data are lacking in HK, and further study in this area is highly warranted.

The majority of the patients within the adherent group belonged to group D, with a higher intrinsic risk of recurrent exacerbations. After the adjustment of other confounding variables, including COPD groupings and history of AECOPD 1 year before study enrollment, the guideline adherence status was not associated with subsequent risk of AECOPD.

Various comorbidities are commonly associated with COPD. As recommended in the GOLD guideline, management of COPD patients must include identification and treatment of these comorbidities. ${ }^{7}$ The concern of COPD-related comorbidities has been rising in recent years due to their significant negative impact on patient outcome. A "solar system" like COPD comorbidome was introduced by the BODE collaborative group recently, incorporating the prevalence and strength of the association between the disease and risk of death. ${ }^{16}$ The interrelationship between clinical characteristics and comorbidities was also quantified by the same study group in a lung-shaped layout network. ${ }^{34}$

In the current study, we evaluated commonly found comorbidities in our locality. In all, $80.9 \%$ of our patients had coexisting comorbidities, which exceeded those reported in the EPIC and EPOCA studies (39\% and 42\%, respectively), ${ }^{3,18}$ probably due to different patient populations and methodologies. HT, diabetes mellitus, ischemic heart disease and old tuberculosis are the common comorbidities in the current and various local and overseas studies. ${ }^{16,17,34}$ Three aspects of barriers for comorbidity detection have been described by Maurer et al, ${ }^{35}$ including patient-perceived, physician-perceived and system-level barriers. ${ }^{36,37}$ As cumulating evidence is now available for the management of these comorbidities, ${ }^{38}$ a well-structured screening protocol or program-based multimodality COPD care service should be developed. Obesity and advanced age were found to be associated with the presence of comorbidities, as they are believed to be common risk factors shared by COPD and certain comorbidities. ${ }^{39}$

There were several limitations in our study. First, as an observational study with a self-reporting mechanism, treatment details including reasons for nonadherence and medication change might not be always available due to recall bias. Second, the COPD groupings could be different if the attending physician chose to use one instead of another factor, for example, to use mMRC score instead of CAT score. This difference could affect the choice of pharmacological treatment significantly. ${ }^{40,41}$ Third, the sample size was not large enough to predict the effect of treatment nonadherence on mortality, COPD exacerbation and pneumonia due to ICS overuse. Fourth, as our study did not require a thorough screening of comorbidities and no management modification was made to the clinical follow up, there might be a possibility of underreporting of comorbidities. Finally, the study population skewed toward groups B and D due to high mMRC or CAT scores, which signified that the patients were highly selective and this might not completely reflect 
the usual pattern of disease burden. ${ }^{3}$ This distribution of disease grouping may therefore limit the generalizability of the results.

\section{Conclusion}

In summary, the current study involving subjects with typical COPD clinical characteristics demonstrated a suboptimal adherence to GOLD guideline 2011 and overtreatment, especially overprescription of ICS. The most commonly found COPD-related comorbidities also aligned with the trend observed in local and nation-wide observational cohorts.

\section{Acknowledgment}

The five hospitals received an unrestricted financial grant from Novartis Pharmaceuticals (HK) Ltd.

\section{Disclosure}

All authors reported no conflicts of interest in this work and received no personal fee from any grant or commercial companies.

\section{References}

1. World Health Organization. World Health Statistics. Geneva: World Health Organization; 2008.

2. Tobacco Control Office, Department of Health. Smoking Cessation Information. Hong Kong: Tobacco Control Office, Department of Health; 2015.

3. Lim S, Lam DC, Muttalif AR, et al. Impact of chronic obstructive pulmonary disease (COPD) in the Asia-Pacific region: the EPIC Asia population-based survey. Asia Pac Fam Med. 2015;14(1):4.

4. Chan-Yeung M, Lai CK, Chan KS, et al; Hong Kong Thoracic Society. The burden of lung disease in Hong Kong: a report from the Hong Kong Thoracic Society. Respirology. 2008;13(suppl 4):S133-S165.

5. Jencks SF, Williams MV, Coleman EA. Rehospitalizations among patients in the Medicare fee-for-service program. N Engl J Med. 2009; 360(14):1418-1428.

6. Shah T, Churpek MM, Coca Perraillon M, Konetzka RT. Understanding why patients with COPD get readmitted: a large national study to delineate the Medicare population for the readmissions penalty expansion. Chest. 2015;147(5):1219-1226.

7. Global initiative for chronic obstructive lung disease (GOLD). Committee. Global Strategy for the Diagnosis, Management and Prevention of Chronic Obstructive Pulmonary Disease. 2011. Available from: http:// www.goldcopd.org/Guidelines/guidelines-resources.html. Accessed August 13, 2013.

8. Edep ME, Shah NB, Tateo IM, Massie BM. Differences between primary care physicians and cardiologists in management of congestive heart failure: relation to practice guidelines. J Am Coll Cardiol. 1997;30(2): $518-526$.

9. Sharif R, Cuevas CR, Wang Y, Arora M, Sharma G. Guideline adherence in management of stable chronic obstructive pulmonary disease. Respir Med. 2013;107(7):1046-1052.

10. Centers for Disease Control and Prevention (CDC). Chronic obstructive pulmonary disease and associated health-care resource use - North Carolina, 2007 and 2009. MMWR Morb Mortal Wkly Rep. 2012;61(8): 143-146.

11. Price D, West D, Brusselle G, et al. Management of COPD in the UK primary-care setting: an analysis of real-life prescribing patterns. Int J Chron Obstruct Pulmon Dis. 2014;9:889-904.
12. Perez X, Wisnivesky JP, Lurslurchachai L, Kleinman LC, Kronish IM. Barriers to adherence to COPD guidelines among primary care providers. Respir Med. 2012;106(3):374-381.

13. Salinas GD, Williamson JC, Kalhan R, et al. Barriers to adherence to chronic obstructive pulmonary disease guidelines by primary care physicians. Int J Chron Obstruct Pulmon Dis. 2011;6:171-179.

14. Chiang CH, Liu SL, Chuang CH, Jheng YH. Effects of guideline-oriented pharmacotherapy in patients with newly diagnosed COPD: a prospective study. Wien Klin Wochenschr. 2013;125(13-14):353-361.

15. Asche CV, Leader S, Plauschinat C, et al. Adherence to current guidelines for chronic obstructive pulmonary disease (COPD) among patients treated with combination of long-acting bronchodilators or inhaled corticosteroids. Int J Chron Obstruct Pulmon Dis. 2012;7:201-209.

16. Divo M, Cote C, de Torres JP, et al; BODE Collaborative Group. Comorbidities and risk of mortality in patients with chronic obstructive pulmonary disease. Am J Respir Crit Care Med. 2012;186(2):155-161.

17. Au LH, Chan HS. Severity of airflow limitation, co-morbidities and management of chronic obstructive pulmonary disease patients acutely admitted to hospital. Hong Kong Med J. 2013;19(6):498-503.

18. Miravitlles M, Murio C, Tirado-Conde G, et al. Geographic differences in clinical characteristics and management of COPD: the EPOCA study. Int J Chron Obstruct Pulmon Dis. 2008;3(4):803-814.

19. Miller MR, Hankinson J, Brusasco V, et al. Standardisation of spirometry. Eur Respir J. 2005;26(2):319-338.

20. Quanjer PH, Stanojevic S, Cole TJ, et al. Multi-ethnic reference values for spirometry for the 3-95-yr age range: the global lung function 2012 equations. Eur Respir J. 2012;40(6):1324-1343.

21. Regional COPD Working Group. COPD prevalence in 12 Asia-Pacific countries and regions: projections based on the COPD prevalence estimation model. Respirology. 2003;8(2):192-198.

22. Turan O, Emre JC, Deniz S, Baysak A, Turan PA, Mirici A. Adherence to current COPD Guidelines in Turkey. Expert Opin Pharmacother. 2016;17(2):153-158

23. Calverley PM, Anderson JA, Celli B, et al; TORCH Investigators. Salmeterol and fluticasone propionate and survival in chronic obstructive pulmonary disease. $N$ Engl J Med. 2007;356(8):775-789.

24. Tashkin DP, Celli B, Senn S, et al; UPLIFT Study Investigators. A 4-year trial of tiotropium in chronic obstructive pulmonary disease. N Engl J Med. 2008;359(15):1543-1554.

25. Wedzicha JA, Banerji D, Chapman KR, et al; FLAME Investigators. Indacaterol-glycopyrronium versus salmeterol-fluticasone for COPD. N Engl J Med. 2016;374(23):2222-2234.

26. Maio S, Baldacci S, Martini F, et al; COMODHES Study Group. COPD management according to old and new GOLD guidelines: an observational study with Italian general practitioners. Curr Med Res Opin. 2014;30(6):1033-1042.

27. Miravitlles M, Sicras A, Crespo C, et al. Costs of chronic obstructive pulmonary disease in relation to compliance with guidelines: a study in the primary care setting. Ther Adv Respir Dis. 2013;7(3): 139-150.

28. Papala M, Kerenidi N, Gourgoulianis KI. Everyday clinical practice and its relationship to 2010 and 2011 GOLD guideline recommendations for the management of COPD. Prim Care Respir J. 2013;22(3): 362-364.

29. Spencer S, Karner C, Cates CJ, Evans DJ. Inhaled corticosteroids versus long-acting beta2-agonists for chronic obstructive pulmonary disease. Cochrane Database Syst Rev. 2011;7(12):CD007033.

30. Kew KM, Seniukovich A. Inhaled steroids and risk of pneumonia for chronic obstructive pulmonary disease. Cochrane Database Syst Rev. 2014;(3):CD010115.

31. Cabana MD, Rand CS, Powe NR, et al. Why don't physicians follow clinical practice guidelines? A framework for improvement. JAMA. 1999; 282(15):1458-1465.

32. Desalu OO, Onyedum CC, Adeoti AO, et al. Guideline-based COPD management in a resource-limited setting - physicians' understanding, adherence and barriers: a cross-sectional survey of internal and family medicine hospital-based physicians in Nigeria. Prim Care Respir J. 2013;22(1):79-85. 
33. Overington JD, Huang YC, Abramson MJ, et al. Implementing clinical guidelines for chronic obstructive pulmonary disease: barriers and solutions. J Thorac Dis. 2014;6(11):1586-1596.

34. Divo MJ, Casanova C, Marin JM, et al; BODE Collaborative Group. COPD comorbidities network. Eur Respir J. 2015;46(3):640-650.

35. Maurer J, Rebbapragada V, Borson S, et al; ACCP Workshop Panel on Anxiety and Depression in COPD. Anxiety and depression in COPD: current understanding, unanswered questions, and research needs. Chest. 2008;134(4 suppl):43S-56S.

36. Vanfleteren LE, Franssen FM, Uszko-Lencer NH, et al. Frequency and relevance of ischemic electrocardiographic findings in patients with chronic obstructive pulmonary disease. Am J Cardiol. 2011;108(11): 1669-1674.

37. Triest FJ, Franssen FM, Spruit MA, Groenen MT, Wouters EF, Vanfleteren LE. Poor agreement between chart-based and objectively identified comorbidities of COPD. Eur Respir J. 2015;46(5): 1492-1495.
38. Vanfleteren LE, Spruit MA, Wouters EF, Franssen FM. Management of chronic obstructive pulmonary disease beyond the lungs. Lancet Respir Med. 2016;4(11):911-924.

39. Brown JP, Martinez CH. Chronic obstructive pulmonary disease comorbidities. Curr Opin Pulm Med. 2016;22(2):113-118.

40. Huang WC, Wu MF, Chen HC, Hsu JY, TOLD Group. Features of COPD patients by comparing CAT with $\mathrm{mMRC}$ : a retrospective, crosssectional study. NPJ Prim Care Respir Med. 2015;25:15063.

41. Zogg S, Dürr S, Miedinger D, Steveling EH, Maier S, Leuppi JD. Differences in classification of COPD patients into risk groups A-D a cross-sectional study. BMC Res Notes. 2014;7:562.

International Journal of COPD

\section{Publish your work in this journal}

The International Journal of COPD is an international, peer-reviewed journal of therapeutics and pharmacology focusing on concise rapid reporting of clinical studies and reviews in COPD. Special focus is given to the pathophysiological processes underlying the disease, intervention programs, patient focused education, and self management protocols.

\section{Dovepress}

This journal is indexed on PubMed Central, MedLine and CAS. The manuscript management system is completely online and includes a very quick and fair peer-review system, which is all easy to use. Visit http://www.dovepress.com/testimonials.php to read real quotes from published authors.

Submit your manuscript here: http://www.dovepress.com/international-journal-of-chronic-obstructive-pulmonary-disease-journal 